\title{
IDOSOS VítIMAS DE ABUSO SEXUAL: ATUAÇÃO DO ENFERMEIRO FORENSE
}

\author{
ELDERLY VICTIMS OF SEXUAL ABUSE: ACTING OF THE FORENSIC \\ NURSE
}

\author{
Fihama Pires Nascimento ${ }^{1}$ \\ Lindemberg Arruda Barbosa ${ }^{2}$ \\ Renata Clemente dos Santos ${ }^{3}$ \\ Emanuella de Castro Marcolino ${ }^{4}$
}

\begin{abstract}
RESUMO: OBJETIVO: Identificar na literatura a atuação do enfermeiro forense a idosos vítimas de violência sexual. MÉTODO: Trata-se de um estudo de revisão bibliográfica da literatura, apresentando caráter descritivo e documental, consultado na plataforma Biblioteca Virtual de Saúde (BVS), na base de dados Literatura Latinoamericana e do Caribe em Ciências da Saúde (LILACS) e na base de dados Scientific Electronic Library Online (SciElo), bem como nos sites da Associação Brasileira de Enfermagem Forense (ABEFORENSE) e do Conselho Federal de Enfermagem (COFEN). Inicialmente foram encontrados 143 artigos e após os critérios de inclusão e exclusão permaneceram 4 estudos que responderam aos objetivos da pesquisa, nos sites oficiais foram encontrados 2 documentos, totalizando assim, 6 manuscritos para a composição da amostra da presente revisão. RESULTADOS: Dentre as violências sofridas por idosos, o abuso sexual mostra-se presente, sobretudo esses crimes na sua grande maioria, são efetuados por indivíduo do convívio social da vítima, deixando sequelas físicas e psicológicas alarmantes, no qual a atuação da enfermagem forense se inicia na detecção da violência seguida de intervenções de acordo com a lei jurídica brasileira, de modo que age coletando provas do crime, preservando vestígios e oferecendo cuidados legais. CONCLUSÃO: A presença do enfermeiro forense é de extrema importância a fim de oferecer recursos de assistência aos idosos vítimas de abuso sexual contribuindo para resolução do delito.
\end{abstract}

\footnotetext{
1 Discente do curso de Enfermagem na UNIFACISA Centro Universitário; E-mail: fihamapires0@gmail.com.

2 Discente do curso de Enfermagem na UNIFACISA Centro Universitário; E-mail: lindemberg.uf@gmail.com.

3 Docente do curso de Enfermagem da UNIFACISA Centro Universitário. Doutoranda em Enfermagem pela UFPB; E-mail: renata.clemente@hotmail.com.

${ }^{4}$ Docente do curso de Enfermagem da UNIFACISA Centro Universitário. Doutora em Enfermagem pela UFRN; E-mail: emanuella.de.castro@gmail.com.
} 
Palavras chave: Abuso Sexual; Enfermagem Forense; Idosos; Maus-tratos ao idoso; Violência.

ABSTRACT: OBJECTIVE: to identify in literature the acting of forensic nurses to elderly victims of sexual violence. METHOD: this is a descriptive and documentary literature review study, consulted on the Virtual Health Library (BVS) platform, the Latin American and Caribbean Health Sciences Literature (LILACS) and in the database of the Online Scientific Electronic Library (SciELO), as well as on the websites of the Brazilian Association of Forensic Nursing (ABEFORENSE) and the Federal Council of Nursing (COFEN). Initially, 143 articles were found and after filtering, 4 studies that met the research objectives were selected, on the official websites were found 2 documents, thus totaling 6 documents for the composition of this review. RESULTS: among the violence suffered by the elderly, sexual abuse is present, especially the crimes for the most part, are committed by individuals living with victims, leaving physical and severe psychological consequences, forensic nursing practice start detecting violence followed in accordance with Brazilian law, so that gathers evidence of crime, preserving traces and legal practices. CONCLUSION: the presence of the forensic nurse is extremely important and offers resources to assist the elderly victims of sexual abuse, contributing to the resolution of the crime.

Keywords: Sexual abuse; Nursing forensics; Seniors; Elder abuse; Violence. 


\section{INTRODUÇÃO}

A violência é um problema social de grande dimensão que atinge pessoas de todas as idades, gerando adoecimento e mortes, afetando a expectativa de vida do país, bem como a qualidade de vida da população, necessitando de intervenções políticas para resolução dessa problemática (LIMA, et.al 2009).

A geriatria é uma especialidade na enfermagem que tem como finalidade ampla buscar o envelhecimento felicito. Entretanto, idosos de diferentes grupos sociais, são vítimas de violência, entre as suas tipologias encontra-se: abuso físico, emocional, financeiro e sexual (ALVES, 2004).

Segundo (Ministério da saúde, 2009) existem cerca de quatro tipos abusos sexuais dos quais podem ser acometidos em idosos, são eles: Atentado violento ao pudor: práticas sexuais sem consentimento, estupro: relação vaginal sem o consentimento da vítima, assédio sexual: utilização da hierarquia a favor de constranger a vítima, ações essas com cunho sexual e exploração sexual: o uso sexual de pessoas para fins lucrativos.

Os principais perpetradores de abusos contra idosos se encontram no âmbito domiciliar, cenário esse que dificulta na identificação da hostilidade, já que o crime pode sensibilizar o psicológico da vítima de forma que optem por recusar a revelar o agressor por se tratar de alguém próximo do seu convívio social. Em vista disso, a dificuldade de expor o abuso sexual que sofre, torna-se um desafio demasiado a coleta de dados notificados no SINAN (Sistema de Informação Nacional de Agravos de Notificação Compulsória) e consequentemente, um panorama real das situações (OLIVEIRA, 2018).

É dever do profissional de saúde registrar as notificações compulsórias de doenças e agravos, gerando vereditos em competência das esferas governamentais de modo que efetive cuidados de saúde para com a vítima, criando estratégias epidemiológicas em busca da prevenção do fenômeno (OLIVEIRA, 2018). 
A enfermagem forense (EF) surge como uma nova especialidade na área da enfermagem que tem como objetivo prestar assistência a vítima, assim como ao agressor do crime, com destaque em notificar e coletar dados da violação acometida, da mesma maneira que auxilia na investigação e busca de evidência para o levantamento do caso; o profissional dessa área deve estar apto a lidar com lesões físicas, psicológicas e sociais de cada cenário da violência que testemunhar (COFEN, 2017).

De acordo com a ABEForense (Associação Brasileira de Enfermagem Forense) a prática da EF é caracterizada por integrar ao mesmo tempo atendimentos jurídicos e de saúde. Tem como papel orientar a vítima para o especialista mais indicado, bem como prestar depoimentos em tribunais, tendo como resultado a possível resolução do delito (ABEFORENSE, 2016).

Nessa área da enfermagem existem diversas competências técnicas para a investigação do crime, uma delas é o abuso sexual, fato que também decorre na área geriátrica, contudo não possui uma notificação eficaz por dificuldade do profissional em identificar o abuso acometido no paciente, veracidade essa que transcorre por erros do próprio profissional ou por quietação do indivíduo, enredando a efetuação de assistência obrigatória do profissional para com a vítima. (ABEFORENSE, 2016).

Desse modo, questiona-se: Qual a atuação do enfermeiro forense na abordagem de situações de abuso sexual contra idosos? Então, o estudo tem como objetivo identificar na literatura a atuação de enfermeiro forense a idosos vítimas de violência sexual.

\section{METODOLOGIA}

Trata-se de um estudo de revisão bibliográfica da literatura, apresentando caráter descritivo e documental. A metodologia técnica é dividida em cinco etapas: 1) identificação do problema de pesquisa; 2) coleta de dados; 3) avaliação dos dados; 4) exposição e interpretação. 
Foi determinada a pergunta de pesquisa seguindo a estratégia de PICo, em que P (paciente) refere-se a idosos vítimas de abuso sexual; I (interesse) a atuação do enfermeiro forense a idosos vítimas de violência e Co (contexto) a enfermagem forense.

Para a coleta de dados foram utilizados os descritores "maus-tratos ao idoso", "violência", "enfermagem forense", "abuso sexual" e "idosos" determinados pela plataforma Descritores em Saúde (DeCs), e cruzados aplicando o operador booleano "AND" na Biblioteca Virtual de Saúde (BVS), repositório bibliográfico da produção científica Literatura Latino-americana e do Caribe em Ciências da Saúde (LILACS) e na base de dados Scientific Electronic Library Online (SciElo); em complemento foram utilizados o site da ABEforese (Associação Brasileira de Enfermagem Forense) e a resolução regulamentada atuação do enfermeiro forense do COFEN (Conselho Federal de Enfermagem), resultando em uma revisão qualitativa.

A princípio, foram encontrados nas bases de dados 143 manuscritos, sendo; 110 na BVS; 15 no SCIELO e 18 no LILACS, aplicando-se os filtros de inclusão: idioma português, citável, artigos e tese, trabalho completo, resultando em 59 manuscritos na BVS, 15 no SCIELO e 6 no LILACS. Em seguida, utilizou-se o critério de exclusão: trabalhos duplicados. 
Figura 1 - Fluxograma de seleção dos artigos científicos nas bases de dados BVS, SciElo e LILACS, e documentos oficiais:

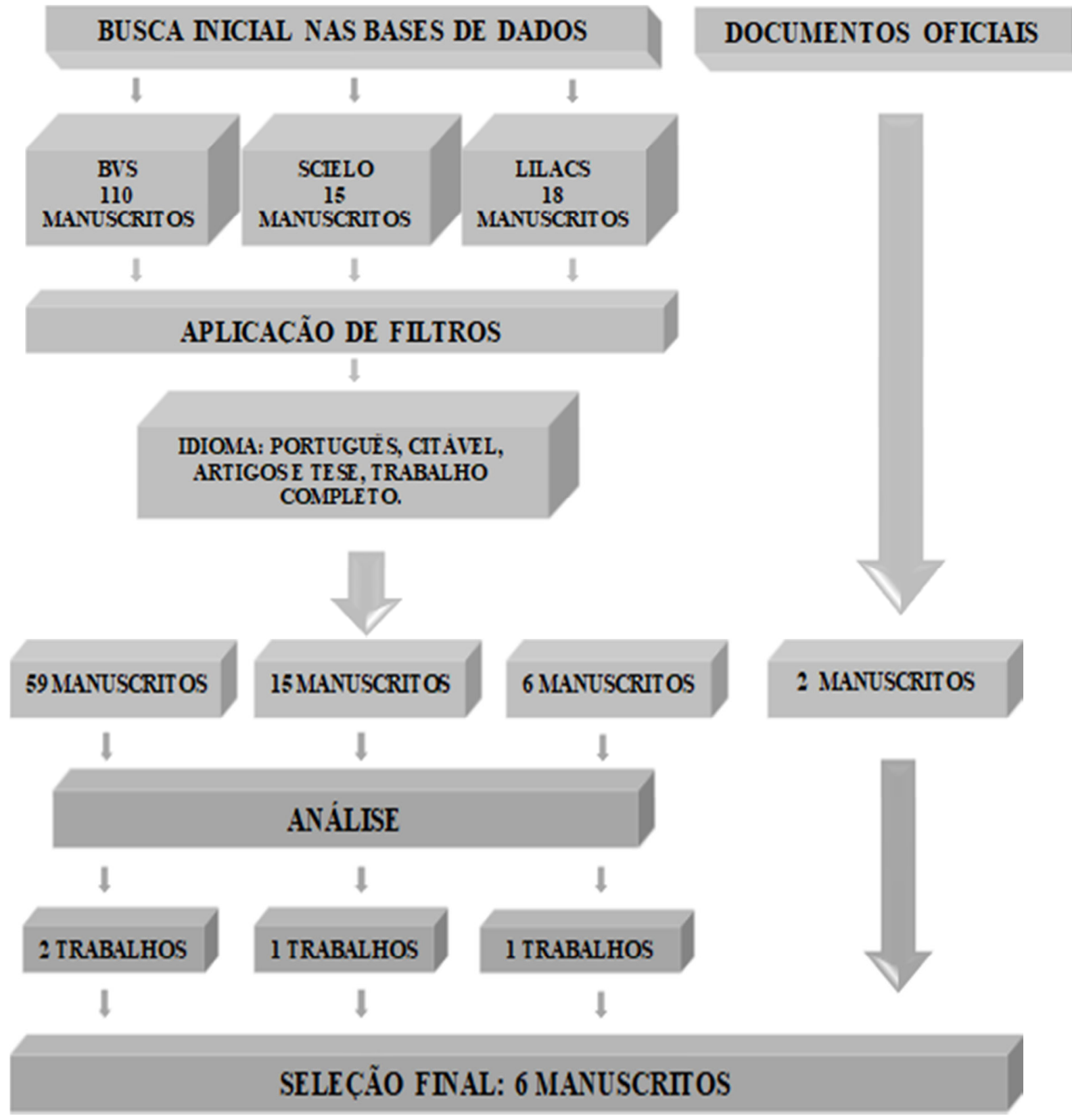

Fonte: autoria própria.

Mediante a leitura destes, foram selecionados apenas os que respondiam ao objetivo da pesquisa e propuseram a amostra de 4 trabalhos, auxiliando no desenvolvimento da presente revisão. Desse modo, a seleção final foram 6 
manuscritos, quatro decorrentes das bases de dados e 2 documentos oficiais da busca nos sites supracitados.

Sendo assim, o trabalho fluiu a partir do método conceitual-analítico, visto que trata- se de uma revisão de literatura, no qual utilizou-se conceitos e ideias de outros autores semelhantes com os nossos objetivos, bem como, decretos e leis para a construção de uma análise científica, com propósito de expor a importância da enfermagem forense no âmbito profissional médico e jurídico (ABEFORENSE, 2016).

\section{RESULTADOS}

No quadro 1 abaixo, detalha-se as características dos estudos selecionados nas bases de dados, observa-se a escassez de estudos atualizados sobre a temática, bem como predomínio de estudos com abordagem quantitativa.

Quadro 1 - Descrição dos estudos científicos selecionados nas bases de dados BVS, SciELo, LILACS quanto a autores, ano de publicação e abordagem do estudo:

\begin{tabular}{|c|c|c|c|}
\hline $\begin{array}{c}\text { CÓDIGO DO } \\
\text { MANUSCRITO }\end{array}$ & AUTOR & ANO & ABORDAGEM DO ESTUDO \\
\hline F1 & ALVES, J.F & 2004 & Qualitativa e Quantitativa \\
\hline F2 & LIMA, M. L. C et al & 2009 & Quantitativa \\
\hline F3 & SILVA, & 2009 & Qualitativa \\
\hline F4 & K.B; SILVA, R. C. & & Quantitativa \\
\hline
\end{tabular}

Fonte: autoria própria.

No quadro 2, foca-se na descrição das intervenções do enfermeiro forense contra as situações de abuso sexual, observa-se que a enfermagem forense é uma especialização que faz ligação entre meios do cuidado e jurídico, em busca da qualidade de vida do paciente e da justiça perante a violência sofrida, atuando de forma significativa na detecção dos primeiros sinais e sintomas presentes na vítima, a fim de tomar iniciativas de acordo com o que lhe é imposto. 
Quadro 2 - Descrição das intervenções do enfermeiro forense para situações de abuso sexual contra o idoso de acordo com os estudos científicos selecionados nas bases de dados BVS, SciELo e LILACS:

\begin{tabular}{|c|c|c|}
\hline $\begin{array}{l}\text { CÓDIGO DO } \\
\text { MANUSCRITO }\end{array}$ & OBJETIVO DO ESTUDO & INTERVENÇÕES DO ENFERMEIRO FORENSE \\
\hline F1 & $\begin{array}{l}\text { Explorar o conceito de abuso } \\
\text { de idosos e resumir os } \\
\text { principais indicadores e fatores } \\
\text { de risco para o abuso. }\end{array}$ & $\begin{array}{l}\text { É imprescindível que o profissional de saúde perceba } \\
\text { sinais e sintomas de abuso em idosos, colocando em } \\
\text { rotina a identificação do grau do abuso acometido, em } \\
\text { seguida, atuar de forma profissional para a justiça do } \\
\text { saso. Em situações cujos sinais não sejam de fácil } \\
\text { cidentificação, o profissional deve saber os fatores de } \\
\text { riscos associado a violência, são eles: o idoso evita } \\
\text { contato visual, medo do parente e/ou cuidador, } \\
\text { depressão, ansiedade, insônia e comportamentos } \\
\text { incomuns. }\end{array}$ \\
\hline $\mathrm{F} 2$ & $\begin{array}{l}\text { Realizar uma análise } \\
\text { diagnóstica dos sistemas de } \\
\text { saúde com relação à atenção } \\
\text { prestada aos idosos vítimas de } \\
\text { acidentes e violências no } \\
\text { Recife. }\end{array}$ & $\begin{array}{l}\text { Para a detecção da violência, a área da saúde é vista } \\
\text { como significativa, é de extrema importância que os } \\
\text { profissionais que ali se encontra, identifiquem sinais e } \\
\text { sintoma de agressão na vítima em primeira instancia, } \\
\text { prestando cuidados de acordo com seus } \\
\text { conhecimentos científicos. }\end{array}$ \\
\hline F3 & $\begin{array}{l}\text { Relatar como ocorre a atuação } \\
\text { da enfermagem forense nos } \\
\text { Estados Unidos da América. }\end{array}$ & $\begin{array}{l}\text { Desencadeado pelo o aumento da violência, a } \\
\text { qualificação do preparo profissional na realização de } \\
\text { crimes se tornou um fato na enfermagem, a prática da } \\
\text { perícia é uma realidade do enfermeiro forense, } \\
\text { atuando de forma grupal com médicos legistas e } \\
\text { policiais na resolução de casos criminais como o } \\
\text { abuso sexual, realizando coleta de DNA e outras } \\
\text { buscas necessárias que indicam a prática e } \\
\text { hostilidade do caso. }\end{array}$ \\
\hline F4 & $\begin{array}{l}\text { Descrever o conhecimento de } \\
\text { profissionais que atuam no } \\
\text { departamento de emergência } \\
\text { do Hospital de Urgências de } \\
\text { Sergipe (HUSE), no estado de } \\
\text { Sergipe, Nordeste do Brasil, } \\
\text { sobre a preservação de traços } \\
\text { forenses e sua capacidade de } \\
\text { implementar na prática os } \\
\text { processos } \\
\text { necessários. relacionados }\end{array}$ & $\begin{array}{l}\text { O profissional dessa área deve estar apto a lidar com } \\
\text { mortes e tragédias, bem como preparados para o } \\
\text { reconhecimento, coleta de dados, armazenamento e } \\
\text { preservação de todo vestígio físico, pois qualquer } \\
\text { interferência externa pode inferir na resolução do } \\
\text { delito. }\end{array}$ \\
\hline
\end{tabular}

Fonte: autoria própria.

No quadro 3 menciona-se as ações do enfermeiro forense de acordo com os documentos oficiais brasileiros, descrevendo de forma clara e objetiva o papel desse profissional no amparo ao paciente vítima do abuso sexual. 
Quadro 3 - Descrição das orientações da atuação do enfermeiro forense no Brasil em situação de abuso sexual contra idosos:

\begin{tabular}{|c|c|c|}
\hline AUTARQUIA FEDERAL & DOCUMENTO LEGAL & $\begin{array}{c}\text { ORIENTAÇÃO PARA O ENFERMEIRO } \\
\text { FORENSE }\end{array}$ \\
\hline ABEForense & $\begin{array}{l}\text { REGULAMENTO } \\
\text { COMPETÊNCIAS DAS } \\
\text { TÉCNICAS } \\
\text { ENFERMAGEM FORENSE. }\end{array}$ & $\begin{array}{l}\text { Identificar sinais e sintomas de agressão na } \\
\text { vítima, prestando cuidados de enfermagem } \\
\text { para a recuperação da saúde do indivíduo, } \\
\text { assim como coletar provas materiais como } \\
\text { amostra de DNA do agressor que será } \\
\text { decretado o registro criminal diante o sistema } \\
\text { S de banco de dados criminais, caso o mentor do } \\
\text { crime não for conhecido pela a vítima. } \\
\text { A Contudo, havendo o consentimento da vítima } \\
\text { C. sobre quem é o agressor, a amostra do DNA } \\
\text { será feita diretamente no suspeito, e se houver } \\
\text { a confirmação da prova, o agressor irá } \\
\text { responder judicialmente perante as leis do país. } \\
\text { Ademais, é dever do enfermeiro forense } \\
\text { proteger e guardar provas do estelionato, bem } \\
\text { como, prestar assistência ao autor do crime. }\end{array}$ \\
\hline COFEN & $\begin{array}{l}\text { RESOLUÇÃO } \\
\text { REGULAMENTADA DE } \\
\text { ENFERMEIRO FORENSE. }\end{array}$ & $\begin{array}{l}\text { O profissional de enfermagem forense deve } \\
\text { prestar assistência a vítima, colher provas do } \\
\text { crime e pode ser submetido a prestar } \\
\text { Edepoimentos em tribunais, além disso, deve } \\
\text { dominar os critérios legais do país e estar } \\
\text { preparado para lidar com traumas físicos e } \\
\text { psicológicos da vítima. }\end{array}$ \\
\hline
\end{tabular}

Fonte: autoria própria.

\section{DISCUSSÃO}

Por se tratar de um grupo vulnerável, a atenção dos sinais e sintomas em idosos precisa ser percebida com máxima atenção, visto que o medo da vítima é grande, fazendo com que recue perante índices de provas realizadas pelo 0 profissional. Ademais, é de extrema importância que o profissional leve em consideração o tempo da vítima em afirmar que sofreu o abuso, sem forçar o paciente em denunciar o crime (OLIVEIRA, 2018). Diante disso, o profissional deve estar apto para atuar na área forense, por meio de estudos especializados (COFEN, 2017). 
No Brasil, os estudos sobre EF ainda são escassos por se tratar de uma área reconhecida a pouco tempo. Iniciou-se a divulgação dessa especialidade, por meios de palestras param docentes e discentes do curso de enfermagem, abrindo espaço para curiosidades de alunos sobre a temática. (SILVA e SILVA, 2009).

Na Europa, a busca do aperfeiçoamento profissional é ampla, visto disso, essa especialização não atua apenas com a vítima, mas sim com toda família, visando reparar os danos causados ao paciente e toda comunidade (MACHADO; ARAÚJO; FIGUEIREDO, 2019).

Já nos EUA, a EF tem prática há mais tempo, seguindo um protocolo imposto para a perícia nos casos de abuso sexual, sendo dado adiante após o consentimento e assinatura da vítima para realizar-se as iniciativas para a resolução do caso pela a equipe forense. Com tudo, a vítima tem o direito de desistir do caso a qualquer momento, mesmo sem que ele tenha sido solucionado (SILVA e SILVA, 2009).

É primordial o conhecimento forense na área de urgência e emergência hospitalar, visto que nesse setor muitos pacientes chegam vítimas do abuso, sendo necessário a atuação do enfermeiro forense na preservação dos vestígios para decisão judicial (MACHADO; ARAÚJO; FIGUEIREDO, 2019).

Diferentes fatores podem contribuir para o despreparo profissional na situação colocado, como a falta de equipamentos que auxiliam a equipe de saúde na preservação de provas e para o atendimento das vítimas e criminosos na penitenciaria, escassez de registros institucionais nacionais e limitação do assunto em graduações e cursos técnicos de enfermagem (OLIVEIRA, 2018).

O diagnóstico do abuso sexual é complexo, exigindo cuidado minucioso na detecção da violência para que sinais fisiológicos do envelhecimento não sejam confundidos com os sinais comuns do delito. Aconselha-se o profissional de EF a realizar perguntas especificas a vítima em um local privado, longe do suposto agressor, à medida que se nota possíveis alterações no estado emocional do idoso, ajudando na identificação precoce do abuso sexual (FERREIRA; SANTOS; VIEIRA, 2015). Para a detecção adequada da violência, o enfermeiro forense necessita de equipamentos adequados de triagem, como uma planilha de questionários, a fim de detectar quaisquer alterações emocionais, físicas e comportamentais, em seguida, 
intervir protegendo a vítima e desenvolvendo atividades psicológicas, bem como de saúde e intervenções legais. (ALON, 2017).

Ao iniciar a busca de evidencias que contaste o abuso sexual acometido, o enfermeiro forense, no EUA, parte do questionário com a vítima em busca de saber como foi o ocorrido, logo após inicia-se os testes de coleta de DNA, realização de fotos da região violentada externa e interna, realizando exame com luz ultravioleta para visualização de substâncias, exames de cavidade oral e genitália, com auxílio de colposcópio, anexado a câmera digital e computador aumentando e gravando a imagem em cores. Em seguida é coletado roupas, e caso a vítima tenha sido submetida ao uso obrigatório de drogas e substâncias suspeitas, são coletados urina e sangue para a investigação forense (SILVA e SILVA, 2009).

A atuação do EF exige sigilo de provas e evidencias, construindo um vínculo de conforto com a vítima e família, ao mesmo tempo em que promove e garante a autonomia da vítima em decidir judicialmente o andamento do caso. Deve haver um equilíbrio na decisão do profissional entre o benefício da vítima, deveres legais e obrigações da sua profissão, bem como manejo em explicar toda situação para o paciente, possa não ter entendimento da condição colocada (FERREIRA; SANTOS; VIEIRA, 2015).

O profissional de EF deve realizar ações terapêuticas para as vítimas que desencadearam transtornos psicológicos devido a violência sofrida, bem como, efetivação destas atividades como forma de prevenir um futuro dano psicológico. Promovendo um ambiente seguro e utilizando seus conhecimentos a fim de propalar cuidados ao paciente (MACHADO; ARAÚJO; FIGUEIREDO, 2019).

Dessa forma, a criação de grupo de apoio a vítimas que sofreram tais agressões, com intervenções psicossociais, como compartilhamento de feedbacks, conselhos e estratégias de comunicação com participantes que sofreram agressões semelhantes, ajuda na autonomia e empedramento do idoso refletindo positivamente e contribuindo na saúde mental do paciente. (MYSYUK; WESTENDORP; LINDENBRG, 2016). 


\section{CONCLUSÃO}

Tratando-se de uma área nova da enfermagem, a diretriz de ação do enfermeiro forense se encontra como algo inovador diante todo sistema judicial e de saúde. Com o aumento global da violência, faz-se necessário implementação da assistência desse profissional na resolução de delitos e na assistência a vítima. Atuando de forma humanizada, priorizando o conforto do paciente quando for realizar coleta de provas. É obrigação do profissional, ser confidencial na realização de sua atividade, mantendo a privacidade do paciente e buscado preservar provas do crime para não interferir no resultado legal.

Ademais, é de extrema importância que o profissional leve em consideração o tempo da vítima em afirmar que sofreu o abuso, podendo aconselhar e incentivar o paciente a realizar a denúncia. Diante disso, o profissional deve estar apto para atuar na área forense, por meio de estudos especializados.

É necessário promover qualidade de estudos forenses para capacitação do enfermeiro nessa área, qualificando o profissional em identificar tais agressões, recolher provas, dominar conhecimento do sistema legal, bem como prestar depoimentos em tribunais, dessa forma, contribui para o impulsionamento na eficácia da justiça para com a vítima, proporcionando uma melhora assistência e contribuindo para o aumento da expectativa de vida.

\section{REFERÊNCIAS BIBLIOGRÁFICAS}

ALON, $\mathrm{S}$ et al. Conscientização dos profissionais sobre abuso sexual na vida adulta: uma pesquisa exploratória. Jornal da Associação Americana De Enfermeiro Psiquiátricos. V. 24, edição: 1, p. 53-61, jun. 2017. Disponível em: <https://doi.org/10.1177/1078390317712598>. Acesso em: 08 de janeiro de 2020.

ALVES, J.F. Factores de risco e indicadores de abuso e negligência de ídoso. Universidade do Minho, Portugal. 2004.Acesso em 02 de janeiro de 2020.

BRASIL. Conselho Federal de enfermagem. 2017. Disponível em: <http://www.cofen.gov.br/resolucao-regulamenta-atuacao-de-enfermeiro- forense_54193.html>. Acesso em 02 de janeiro de 2020. 
BRASIL. Ministério da saúde. Por uma Cultura da Paz, a Promoção da Saúde e a Prevenção da Violência. Brasília. Ministério da Saúde, 2009. 44p (Série F. Comunicação e Educação em Saúde).

Disponível

em:

<http://bvsms.saude.gov.br/bvs/publicacoes/cultura_paz_saude_prevencao_violencia.pdf>Ace

sso em 02 de janeiro de 2020.

FERREIRA, M; SANTOS, C. L; VIEIRA, D. N. Deteção e Estratégias de Intervenção por Parte dos Profissionais dos Cuidados de Saúde Primários na Suspeita de Abuso do Idoso. Rev. Científica Ordem dos Médicos. lisboa, portugal, v. 28, n 6 p. 687-694 nov - dez. 2015. Disponível

em: <https://actamedicaportuguesa.com/revista/index.php/amp/article/view/6706/4546>. Acesso em 07 de jan. 2020.

LIMA, M. L. C et al. Assistência à saúde dos idosos vítimas de acidentes e violência: uma análise de rede de serviços SUS no Recife (PE, Brasil). Universidade Federal de Pernambuco, Recife. 2009.Acesso em 02 de janeiro de 2020.

MACHADO, B. P; ARAUJO, I. M. B; FIGUEIREDO, M. C. B. Enfermagem forense: o que é lecionado na licenciatura de enfermagem em Portugal. Rev. Enf. Ref., Coimbra, v. IV, n.22, p. 43-50, set. 2019 Disponível

em

$<$ http://www.scielo.mec.pt/scielo.php?script=sci_arttext\&pid=S0874-

02832019000300005\&lng=pt\&nrm=iso>. Acesso em 07 janeiro 2020.

MEDEIROS, Z.C. Boas-Vindas. ABEForense, Sergipe, 10 de maio de 2016. Disponível em: <https://www.abeforense.org.br/\#Publicações>. Acesso em 02 de janeiro de 2020.

MEDEIROS, L. V. O. Tutela jurídica do idoso: A assistência e a convivência familiar. 2015. 20p. Trabalo de Conclusão de Curso- Universidade Tiradentes-UNIT. Aracajú. 2015.Acesso em 02 de janeiro de 2020.

MUSSE, J.O et al. Preservação de traços forenses por profissionais de saúde em um hospital no nordeste do brasil, Rev.Forensics Cience International, v. 306, janeiro 2020. disponível em: <https://www.sciencedirect.com/science/article/pii/s0379073819304694>. Acesso em 02 de janeiro de 2020.

MYSYUK, Y; WESTENDORP, R. G .J; LINDENBRG, J. How older persons explain why they became victims of abuse. Rev. Idade e Envelhecimento. V. 45 , edição 5, p. 696- 702,set. 2016. Disponível em: <https://academic.oup.com/ageing/article/45/5/696/1712644>. Acesso em: 07 de janeiro de 2020.

OLIVEIRA, K. S. M et al. Violência contra idosos: concepções dos profissionais de enfermagem acerca da detecção e prevenção. Rev. Gaúcha Enferm. Porto Alegre, v. 39, e.57462, 2018 . Disponível em <http://www.scielo.br/scielo.php?script=sci_arttext\&pid=S1983$14472018000100416 \&$ Ing=pt\&nrm=iso>. Acessos em 08 jan. 2020.

SILVA, K.B; SILVA, R. C. Enfermagem forense: uma especialidade a conhecer. Rev. vou ficar doente. Curitiba, v. 14, n. 3 , p. 564-568, setembro 2009. Disponível em $<$ http://www.revenf.bvs.br/scielo.php?script=sci_arttext\&pid=S1414-

$85362009000300023 \&$ Ing=en\&nrm=iso>. Acesso em 02 de janeiro de 2020. 